\title{
Falando sobre experiências interculturais: o 'salto' cognitivo para o universo do outro ${ }^{1}$
}

\author{
Talking about intercultural experiences: the cognitive 'leap' \\ into another universe
}

\section{Ulrike Agathe Schröder}

Universidade Federal de Minas Gerais - UFMG

\begin{abstract}
Resumo: Com base em análises de sequências filmadas nas quais intercambistas falam sobre suas experiências no exterior, mostraremos como eles conceitualizam tais vivências no plano verbal, vocal e visual-corporal. Os dados provêm do projeto desenvolvido pelo Núcleo Estudos de Comunicação (Inter-)Cultural em Interação NUCOI (<http://www.letras.ufmg.br/nucleos/nucoi/>). Ao tomar como referencial teórico a Linguística Interacional e a abordagem sobre a metáfora cognitiva na sua expressão multimodal-gestual, ilustraremos como a coocorrência de meios lexicais, prosódicos, gestuais e mímicos formam características estilísticas como pistas de contextualização por meio das quais os participantes da fala-em-interação coconstroem suas experiências de forma criativa. Sendo assim, a experiência do 'outro' (otherness), bem como os 'abismos' entre as culturas e o momento do 'salto' para o outro universo incógnito são exibidos metaforicamente por elementos como olhos vastamente esbugalhados, pulos entonacionais, alongamentos, inspirações audíveis, acentos focais extra fortes, expressões lexicais e interjeições de constrangimento e estupefação, bem como gestos que metonimicamente refletem modelos culturais.
\end{abstract}

Palavras-chave: Modelos culturais. Prosódia. Metáfora gestual. Linguística Interacional. Linguística Cognitiva.

\begin{abstract}
Based on the analyses of different videotaped sequences in which exchange students talk about their intercultural experiences abroad, I will show how they conceptualize those experiences on the verbal, vocal, and visual plane. The empirical data originates from the project Intercultural Communication in Interaction (<http://www.letras.ufmg.br/nucleos/nucoi/>). By taking up the theoretical framwork of interactional linguistics, as well as recent research in cognitive metaphor and gesture I will show how the co-occurrence of lexical, syntactic, prosodic, and suprasegmentalphonological as well as gestural and mimic elements form specific stylized features as contextualization cues through which participants in talk-in-interaction co-construct and frame their experiences in creative ways. Thus, the experience of 'otherness', as well as gaps between the cultures and the 'leap' into the new unknown universe, is displayed on the facial level by widened and fluttering eyes, accompanied by verbal expressions of bewilderment and astonishment, and marked prosodically by pitch jumps, lengthenings, or glides endowed with a strong emotional charge. Those examples also illustrate the use of nonverbal hints such as facial expressions and gestural devices which metonymically reflect underlying cultural models.
\end{abstract}

Keywords: Cultural models. Prosody. Gestural metaphor. Interactional linguistics. Cognitive linguistics.

\footnotetext{
${ }^{1}$ Eu agradeço ao CNPq pela Bolsa de Produtividade (2015-2018), à FAPEMIG pelo apoio que recebi e que estou recebendo pelo Programa Pesquisador Mineiro $(2015-2017 ; 2017-2019)$ e agradeço à CAPES e à Fundação Humbold pelo apoio financeiro que recebi dentro do programa CAPES/HUMBOLDT Research Fellowship for experienced researchers para a realização da minha pesquisa de pósdoutorado na Universidade de Münster na Alemanha de agosto de 2013 a julho de 2014. Também agradeço à Profa. Dra. Susanne Günthner pelo convite a trabalhar no Instituto de Estudos Germânicos na WWU, bem como a Martina Hofer da International Office, a Susanne Filler do Departamento ERASMUS e Ricardo Schuch e Luciano Januário de Sales do Brasilienzentrum da WWU pela ajuda na busca de voluntários para minha filmagem. Finalmente, agradeço à Indra Sülzer e a Thomas Böcker pelo apoio técnico durante a filmagem e na transcrição.
} 


\section{Introdução}

Apesar dos efeitos híbridos da globalização, os indivíduos continuam experienciando sua chegada em uma cultura nova como um confronto imediato com novas realidades. Por isso, o objetivo deste trabalho é voltar o olhar para a fala de intercambistas sobre suas primeiras experiências em uma cultura de chegada: como eles retrospectivamente coconstroem suas experiências de 'choques culturais' no plano verbal, vocal e visual?

Questões desse tipo formam a base do nosso Núcleo de Pesquisa Comunicação (Inter-)Cultural em Interação - NUCOI - que foi fundado em 2012 na UFMG $^{2}$. A meta do projeto é a criação de um corpus de vídeos e suas transcrições, que se baseiam em interações entre participantes de culturas diferentes, bem como entre participantes que tenham o mesmo pano de fundo linguístico e cultural, para fins de comparação. No centro das conversas, de maioria eliciadas, estão tópicos interculturais. Dessa forma, busca-se revelar como se constituem processos (auto-)reflexivos em dependência da língua e da cultura, e como eles aparecem nas interações sendo construídos pelos participantes de forma recíproca e multimodal no nível verbal, vocal e visual. Depois das filmagens, as interações são transcritas no programa EXMARaLDA $^{3}$ seguindo as convenções de GAT 2 (SELTING et al., 2016). Com o passar do tempo, um corpus crescente vem sendo gerado, o qual é formado tanto pelos vídeos quanto pelas transcrições correspondentes, dados os quais promovem a base empírica para estudos na interface de três campos de pesquisa: (1) Linguística Cognitiva e Cultural; (2) Pragmática Intercultural; e (3) Análise da Conversa e Linguística Interacional.

\section{Referencial teórico-metodológico}

Na discussão teórica atual, há um crescente diálogo entre a Linguística Cognitiva (LC) e a Análise

\footnotetext{
2 O site do projeto em português pode ser acessado em $<$ http://www.letras.ufmg.br/nucleos/nucoi/>.

${ }^{3}$ http://exmaralda.org/en/
}

da Conversa ( $A C$ ), que parte do insight das duas linhas de pesquisa de que, considerando as questões atuais, já por bastante tempo, as respectivas abordagens apresentam vertentes com visões limitadas: para a LC, esse déficit revela-se sobretudo na crítica veemente que recebe com relação à sua metodologia frequentemente circular, ao seu alto grau de abstração, ao seu individualismo metódico, bem como à abstenção de dados autênticos (SCHRÖDER, 2012,; CHARTERIS-BLACK, 2004,; DEIGNAN, 2005, LANGACKER, 2016, CIENKI, 2016, SARDINHA, 2007, MOURA, 2005).

Por outro lado, abordagens funcionalistas no campo da pragmática e, de forma par excellence, a $A C$ vêm sempre destacando seu interesse exclusivo na determinação dos princípios e mecanismos formais por meio dos quais os participantes de interações naturais em determinado acontecimento social, coletadas através de um procedimento radicalmente empírico, estruturam, ordenam e coordenam sua própria ação, a dos outros e a situação de ação em si (BERGMANN, 1994, SACKS; SCHEGLOFF; JEFFERSON, 1974). Com isso, em oposição à LC, 0 aspecto semântico foi frequentemente excluído do seu objeto de estudo.

Porém, a partir dos anos noventa, também na AC, começaram a surgir vozes críticas relacionadas a um interesse crescente voltado para uma (re-) integração de questões cognitivas, embora até hoje essas questões ainda sejam de fato apenas raramente tratadas de forma explícita na discussão ou nas pesquisas empíricas (DEPPERMANN, 2012; SCHMITZ, 1998). Evidência dessa nova tendência são, entre outros, a análise do "oh" como 'change-ofstate token', conforme Heritage (2002), a proposta de Auer (1996) com relação ao conceito de 'gestalts sintáticos', a virada cognitiva que se deu nos estudos sobre reparo (HAYASHI; RAYMOND; SIDNELL, 2013), os estudos multimodais sobre tokens de afiliação (GOODWIN, 2007; STIVERS, 2008) ou a análise multimodal de elementos envolvidos no estilo de fala enfático (SELTING, 1994, 2013), para nomear apenas alguns. 
Concomitantemente, a Linguística Cognitiva, por sua vez, busca superar as falhas da primeira geração ao direcionar recentemente mais atenção para os aspectos multimodais, contextuais, situacionais e culturais. Com relação à criação de uma interface entre os estudos cognitivos e interacionais, convém salientar a contribuição decisiva dos estudos multimodais à Teoria da Metáfora Conceptual (TMC), especialmente no que tange ao gesto metafórico, a qual leva em conta que metáforas verbais mortas ainda podem ser (re-) processadas ativamente, as quais Cienki e Müller distinguem entre awake e asleep metaphors (CIENKI; MÜLLER, 2008), referencial aplicado por Perlman e Gibbs (2013) também ao gesto vocal. Adicionalmente, Müller e Cienki (2009) distinguem entre metáforas 'monomodais' e 'multimodais', ao se referirem respectivamente a metáforas que ocorrem apenas em um modo, seja ele verbal ou não verbal, e àquelas nas quais os domínios fonte e alvo são representados de forma coexpressiva em ambos os modos na interação. Focalizando igualmente a comunicação real, Mittelberg e Waugh (2009) revelam a importância da interpretação metonímica do gesto como primeiro passo necessário para acessar, em um segundo passo, dado objeto motivado metaforicamente, fenômeno bastante frequente na interação em andamento. A seguir, observaremos a importância destas contribuições dos dois campos de pesquisa para a análise da coconstrução da alteridade nos relatos das experiências interculturais por intercambistas.

\section{Análise}

\subsection{O corpo para o alemão é uma coisa natural}

A primeira sequência faz parte de uma interação intercultural composta por oito estudantes, quatro brasileiras e quatro alemãs, no Brasil. Elas falam sobre o conservadorismo e os bons costumes com respeito à família e às relações amorosas em Minas Gerais:

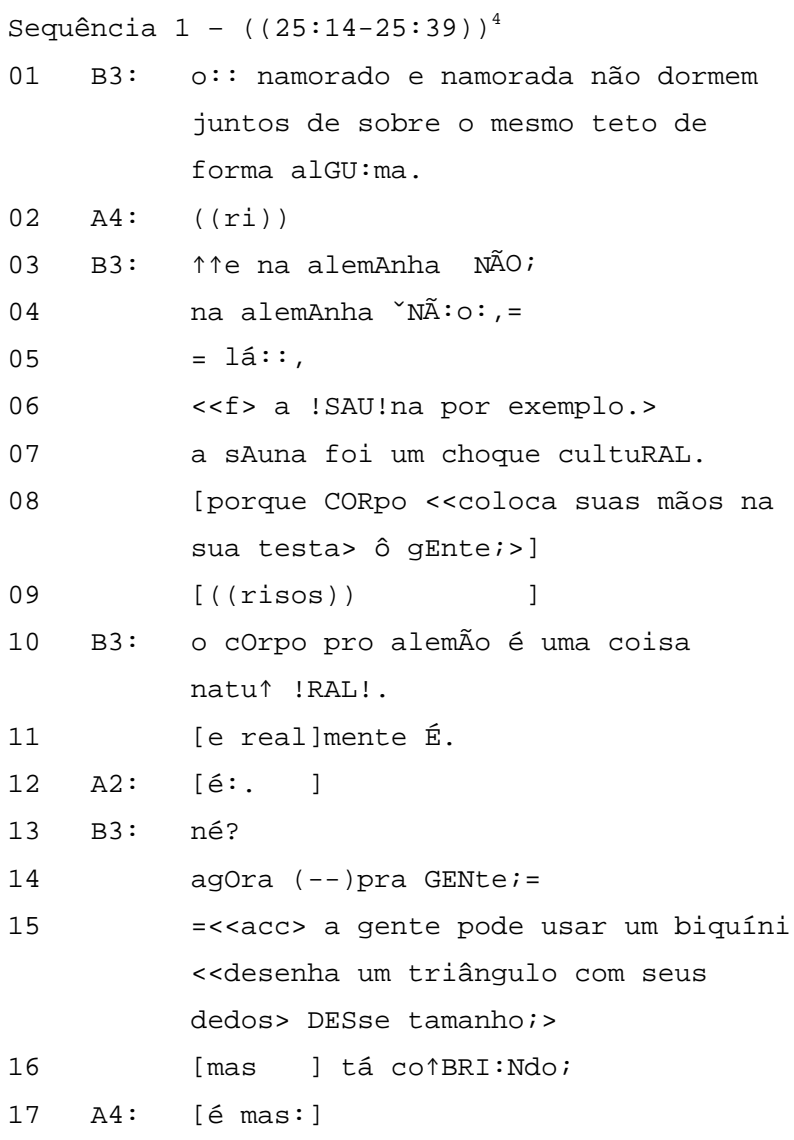

B3 inicia seu turno com uma 'formulação de caso extremo' (extreme case formulation, POMERANTZ, 1986), falando sobre valores e costumes dos pais em Minas Gerais, que de jeito nenhum iriam permitir a seus filhos que passassem a noite junto ao namorado ou à namorada (L01). A seguir, ela postula duas vezes o oposto para a cultura alemã em comparação à brasileira (L02-04), destacando sua afirmação: (i) com o acento focal no lexema-chave NÃO; (ii) com o pulo entonacional para cima no início do turno; (iii) com o movimento entonacional descendente no acento NÃO (L03); e, finalmente, (iv) com o alongamento duplo e o movimento entonacional descendente-ascendente quando repete a negativa: “NÃ:०: (L04). Esta repetição e seu alongamento aponta para o nível cognitivo, em termos de Lakoff e Johnson (2003 [1980], 127), para a metáfora conceptual MORE OF FORM IS MORE OF CONTENT, para a qual os autores dão exemplos como "He is bi-i-i-i-ig!" e "He

\footnotetext{
${ }^{4}$ Todas as sequências podem ser assistidas no seguinte link: https://drive.google.com/open?id=0B4065pqma9RCT3QtS1E1d $\underline{\mathrm{nF} 4 \mathrm{ckE}}$
} 
ran and ran and ran and ran". Por outro lado, os pulos entonacionais e movimentos também refletem um padrão, típico do estilo de fala enfático brasileiro, que já foi identificado como modo de expressão em situações de estupefação e atordoamento (SCHRÖDER; CARNEIRO MENDES, 2016, 2017), o qual pode ser descrito metaforicamente como oscilação entre dois pólos extremos ou domínios consideravelmente distantes entre si. A estupefação continua quando B3 relata sua experiência com a sauna alemã nas linhas 06-10. Aqui, novamente se observa a coocorrência de elementos prosódicos que sublinham a experiência do choque cultural, a qual se torna explícita nesse momento (L07): densidade acentual, acentos focais extrafortes, movimentos entonacionais e mudanças de volume para emocionalizar a experiência da alteridade.

$\mathrm{Na}$ linha 08, B3 insere o metacomentário apelativo ô gEnte e encobre sua face com ambas as mãos, o que é ratificado pelos outros coparticipantes por risos, indicando a afiliação deles. Este gesto representa metonimicamente em um primeiro passo o ato de 'esconder', e manifesta em um segundo passo (MITTELBERG; WAUGH, 2009) a metáfora SHAME IS HIDING AWAY FROM THE WORLD (KÖVECSES, 2003, 32). Em seu estudo diacrônico sobre a conceitualização de VERGONHA em inglês, Heli Tissari (2005) postula que a base esquemática para esta metáfora está interligada ao fato de que, quando as pessoas se sentem envergonhadas, elas simultaneamente sentem vontade de se esconder, desaparecer e diminuir, comportamento que representa o oposto da postura ereta do orgulho.

\subsection{Totalmente retardado}

A próxima sequência provém de uma interação entre quatro estudantes alemães depois da experiência de intercâmbio deles fora do país. Um deles relata um incidente xenófobo relatado a ele por outra intercambista que também estava na Polônia no mesmo período:

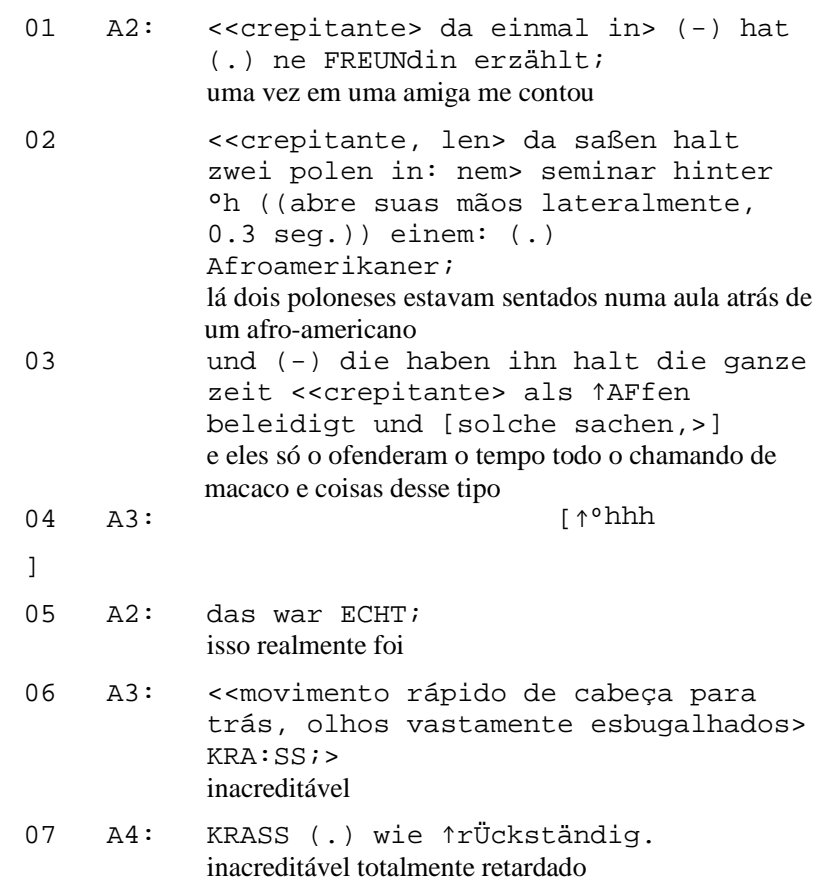

Tomando em consideração a sequência anterior, chama a atenção que o evento chocante aqui é reportado sem as pistas prosódicas que tipicamente marcam um estilo de fala enfático. Muito pelo contrário, na Sequência 2, esse evento é marcado por um estilo que pode ser descrito de forma mais adequada como 'detached style' (CHAFE, 1982). De fato, é graças à qualidade da voz crepitante (creaky voice) usada pelo narrador da história, A2, durante a maioria dos turnos nesta sequência (L01, 02, 03), que se percebe um efeito de uma voz inexpressiva e não flexionada. Lee (2015) estudou cinco tipos de voz crepitante baseando-se em entrevistas. Uma categoria foi denominada de 'uso de voz crepitante para tomar posição' (stance-taking). Nesta categoria, observa-se uma mudança do 'autor' para o 'animador' na terminologia do 'formato de produção' de acordo com Goffman (1981), uma vez que o animador não quer ser associado com o autor do enunciado racista que ele está citando. Destarte, a voz crepitante poderia ser vista outrossim como um dispositivo no plano cognitivo e estar associada à metáfora analisada por Kövecses (2002, p. 213-225) no nível morfossintático, INVOLVEMENT IS CLOSENESS e, consequentemente, LACK OF INVOLVEMENT IS DISTANCE. A mesma relação facilmente pode ser transferida ao nível prosódico sob investigação aqui: o som monótono e afônico do

Sequência $2-((19: 59-20: 11))$ 
relato de A2 incorpora o ponto de vista distante com respeito ao comportamento observado, do qual ele deseja se dissociar. Não se trata de uma reação enfática, mas sim intelectual, ou seja, cognitiva.

A despeito disso, os coparticipantes ratificam a história por meio de um forte envolvimento e do uso de tokens de afiliação. A3 responde com um objeto de som, uma inspiração audível, exprimindo pavor e estupefação (L04). É seguido por um movimento curto da cabeça para trás, acompanhado por olhos vastamente esbugalhados, sobrancelhas levantadas e 0 adjetivo intensificador KRA:SS (inacreditável), que é imediatamente repetido pela coparticipante A4, a qual toma o próximo turno e adiciona seu comentário wie $\uparrow r$ Ückständig (totalmente retardado). Todas estas características em conjunto coconstituem um 'response cry' (GOFFMAN, 1981) para exibir indignação e simultaneamente afiliação e afeto compartilhados.

\subsection{Foi horrível mas também muito engraçado}

$\mathrm{Na}$ última sequência, dois intercambistas alemães e uma sueca recém chegados ao Brasil pela organização Youth for Understanding para um intercâmbio escolar debatem se já enfrentaram situações em que os costumes das pessoas são aceitáveis no Brasil, mas não o seriam no seu país de origem ou vice versa. A participante sueca aponta o que ela chama de 'gay or black people jokes'5: Sequência 3 - ((70:57-71:46))

5 Em nossa discussão nesse artigo, não focalizamos o que realmente aconteceu no momento da enunciação, e nem julgamos o comportamento dos participantes. Porém, nós supomos, a partir do contexto em que a sequência está encaixada e a partir da conversa integral que dura mais do que uma hora no total, que esta não se trata de uma situação que poderia simplesmente ser etiquetada como 'racista' a partir de uma visão 'acadêmica', principalmente se considerarmos a perspectiva dos participantes. Pelos dados aos quais temos acesso por meio do vídeo e das transcrições, as quais podem ser acessadas no site do NUCOI, pela reação da sueca e pelas informações passadas antes e depois desta sequência, parece que o aluno brasileiro que chamou o colega negro de "escravo" na situação em que este ajudou a sueca a carregar a carteira, tomou essa liberdade, pois o colega era amigo dele. O que parece 'racista' à primeira vista para alguns pesquisadores, os quais partem de uma perspectiva de fora, extracomunicativa, não necessariamente parece racista para jovens ingênuos em um contexto participativo de uma situação específica, a partir da visão comunicativa deles, o que, por outro lado, também não exclui a possibilidade de que o aluno que foi chamado de escravo não tenha achado isso nada engraçado. Simplesmente and they make all of GAY jokes;

e eles fazem todas as piadas sobre gay

$<\langle$ rindo $>$ and they make it ALL of; $>$ e eles fazem todas as

$<$ <abrindo e fechando seus olhos

rapidamente> BLACK

[people jokes; $>$ ]

piadas sobre pessoas negras

[ ( (ri))

A2: $\quad[((r i))$

S1: it was ${ }^{\circ} \mathrm{hh}$ it was LIKE;

isto foi tipo

(.) HERE (.) they're like (-) $<<$ aponta com o dedo a comida> thEse; $>$

aqui eles são tipo esses

$\mathrm{xxx}$ )

com as cadeiras com a mesa

$a:$ nd they're like ( $x x x)$, e eles são tipo

so i took aWAY my myentão eu tirei minha minha

(--) chair (-) table (THINGS), cadeira mesa coisas

(.) so i ASKED a guy to help me carry it bAck;

então eu pedi para um cara me ajudar a trazê-la de volta

<<acc> because it's REALly heavy; > pois é realmente pesada

and (.) he happens to agree $\uparrow$ BUTe ele concordou mas

so lucas started call him $\uparrow^{2}$ SLAVE hehehe-

aí lucas começou a chamá-lo de escravo

[ ( (ri)) ]

[<rindo> because he's blAck and HELping me; ]

pois ele é negro e estava me ajudando

18 A2: [( (ri)) ]

19 A1: [( (ri)) ]

20 A1: $[<<$ com olhos vastamente esbugalhados> and I was like; ] e eu tava tipo

21 A2: [( (ri))

22 A1: [( (ri))

( (ri)) ]

23 S1: [(.) Oh my GOD, ]

oh meu deus

24 A2: $\quad[((r i))$

25 A1: $\quad[((r i))$

26 S1: [he's calling THIS guy ${ }^{\circ} \mathrm{h} \mathrm{h}^{\circ} \mathrm{h}^{\circ} \mathrm{h}{ }^{\circ} ;>$ ] ele tá chamando este cara

$\begin{array}{llll}27 & \text { A2: } & {[((r i))} & \\ 28 & \text { A1: } & {[((r i))} \\ 29 & \text { S1: } & {\left[{ }^{\circ} \text { hh } \uparrow \text { it was it was REALly funny so }\right.} \\ & & \text { i wAnted to laugh, }]\end{array}$

não temos acesso a esses dados, só sabemos que, obviamente, na superfície da interação, esta situação não causou nenhuma crise entre os interlocutores. Em oposição a esta, a situação da Sequência 2 já foi muito diferente, o que pode ser comprovado pela reação do participante que, por sua vez, relatou o mal-estar da colega dele que assistiu a ofensa sendo feita de maneira direta e não em tom de 'brincadeira' ao colega afro-americano. 
isto foi isto realmente foi engraçado então eu queria rir

30 A2: $\quad[((r i))]$

31 A1: [( (ri)) ]

32 S1: [but i couldn't do it because

tha:t's (.) so: (.) !AW!ful; ]

mas não consegui pois isso é tão horrível

33 A1: [( (ri)) ]

34 S1: [you can't (-) tell a black person he's a 'SLA:VE;

você não pode dizer para uma pessoa negra que ela é escrava

35 A2: [( (ri)) ]

36 A1: [( (ri)) ]

37 S1: [because he was HELping me>; ]

pois ele estava me ajudando

38 A2: $\quad[((r i))$

39 A1: [( 1 ri $)$

40 S1: [IT was-

isto foi

41 A1: [( (ri)) ]

42 S1: (-) it was AWful;

isto foi horrível

(-) but it was Too very funny; mas também foi muito engraçado

Enquanto a sueca diz BLACK people jokes (L03), no nível não verbal, esta experiência do choque cultural é reencenada metonimicamente pelos olhos vastamente esbugalhados e flutuando como se ela não conseguisse acreditar nos seus olhos quando se vê em meio a esta nova realidade.

Ela estabelece 0 espaço mental (FAUCONNIER, 1985) 'classroom' (L07) ao elaborar o frame para sua história e começa a 'zoom in' (GÜNTHNER, 2011), ao re-entrar no cenário para envolver os coparticipantes em sua narração. $\mathrm{Na}$ linha 14, ela anuncia o clímax por meio do pulo entonacional para cima colocado antes do conector adversativo acentuado BUT, sem terminar a oração. $\mathrm{Na}$ linha 15, o climax da narração é sublinhado pelo deslizamento descendente-ascendente no termochave acentuado $\uparrow^{`}$ SLAVE, seguido por um token de riso curto que enquadra o evento metacomunicativamente como absurdo. Como Jefferson (1979) já advogou, risos frequentemente não apresentam uma reação a um estímulo humorístico, mas sim servem como pista contextual, e no presente caso, o riso representa uma pista para etiquetar a narração executada como inacreditável.

Os dois alemães imediatamente ratificam, por sua vez, o comportamento da sueca através de risos.
Este riso contínuo realça o coalinhamento deles com a interpretação da situação pela falante e serve como continuador.

$\mathrm{Na}$ linha 23, a sueca anuncia sua reação interna pela construção 'like', seguida pela interjeição Oh my GOD; que reflete os pensamentos dela e sua consternação interna, gestualmente corporificada pelos olhos vastamente esbugalhados. Contudo, nas linhas de 29 a 32 , ela admite que oscilou entre 0 desejo de rir e, por outro lado, a consternação que sentiu. Esta tensão é exprimida pela coocorrência de: (i) um onset alto de riso curto no começo da linha 29; (ii) a fala gaguejada e as vogais alongadas na linha 32; (iii) a oposição dos atributos REALly funny $\leftrightarrow$ so: (.) !AW!ful; e (iv) o contraste entre os verbos acentuados wAnted $\leftrightarrow$ cOUldn't (L29 e L32). Tais repetições verbais, pausas e deslizamentos alongados podem ser vistos novamente como expressões multimodais da metáfora descrita acima MORE OF FORM IS MORE OF CONTENT (LAKOFF; JOHNSON, 2003 [1980], 127). Na sua conclusão, a sueca novamente opõe as duas emoções competidoras que ela sentiu: ter experienciado esta situação como horrível e engraçada ao mesmo tempo (L42-43).

Tendo abordado todos os detalhes da sequência acima, seria interessante considerá-la a partir de uma microanálise acerca de seu desdobramento cognitivo de acordo com a Teoria da Mesclagem (FAUCONNIER; TURNER, 2002): a primeira enunciação de interesse, can't (-) tell a black person he's a 'SLA:VE, (L34) poderia ser vista como uma transferência de uma situação que ocorre no Brasil a um sistema de valores culturais pertencente à Suécia (fenômeno chamado na Figura 1 de 'regras do PC fortemente versus fracamente codificadas'). Como defende Alfred Schütz (1976 [1944]), por meio da experiência do deslocamento, o estrangeiro começa a experimentar as limitações do seu 'pensar como costumava' (thinking as usual) e a receita de um padrão costumeiro para pensar e atuar não funciona mais, os sistemas de relevância da pessoa começam a ser abalados. A experiência intercultural emerge na 
mescla como espaço intercultural, mas aqui essa mescla deve ser concebida como um processo em andamento. É por isso que se observa um segundo passo que se torna explícito quando a sueca termina sua narração com a observação it was AWful; (-) but it was Too very funny;, uma vez que esta afirmação se refere ao seu local entre os dois mundos que ela está habitando neste momento. A experiência da alteridade e os abismos entre as culturas não são fixos, mas levam a estados de transgressão, o que é incorporado pelos olhos esbugalhados e flutuantes, uma reação que pode ser interpretada metaforicamente como a experiência de um tipo de 'salto' para o novo universo. Observa-se em detalhe como tal experiência-chave pode induzir o processo de transgressão ainda no estado inicial da ambiguidade sentida, além disso, os pilares fundamentais dos próprios sistemas culturais são colocados em movimento e começam a ser abalados, embora ainda não esteja claro para qual direção este processo vai levar. Observa-se este espaço intercultural como mesclagem de acordo com Fauconnier e Turner (2002) na Figura 1.

\section{Considerações finais}

Ao analisar três exemplos diferentes de falas sobre experiências interculturais, teve-se como objetivo mostrar momentos da coconstrução interacional de relatos de 'choques culturais' no plano verbal, vocal e visual, e observá-los sob as perspectivas, por um lado, da Análise da Conversa e da Linguística Interacional, e por outro lado, da Linguística Cognitiva.

Um resultado decisivo foi que os três modos de comunicação coocorrem e coconstroem o significado que está embutido no contexto interacional. Isto implica no fato de que questões funcionais e conceptuais são interconectadas e encaixadas em um contexto de narração, afiliação e estilo de fala emocionalmente relacionados. Como vimos, por exemplo, o gesto histórica e culturalmente encaixado ENCOBRIR A PRÓPRIA FACE COM AS MÃOS PARA MOSTRAR VERGONHA está relacionado à experiência culturalmente específica de um brasileiro perante a nudez alemã na sauna e representa um dispositivo metonímico-metafórico, adicionalmente embutido em um contexto interacional, o qual serve

para obter 0 riso das
INPUT 1

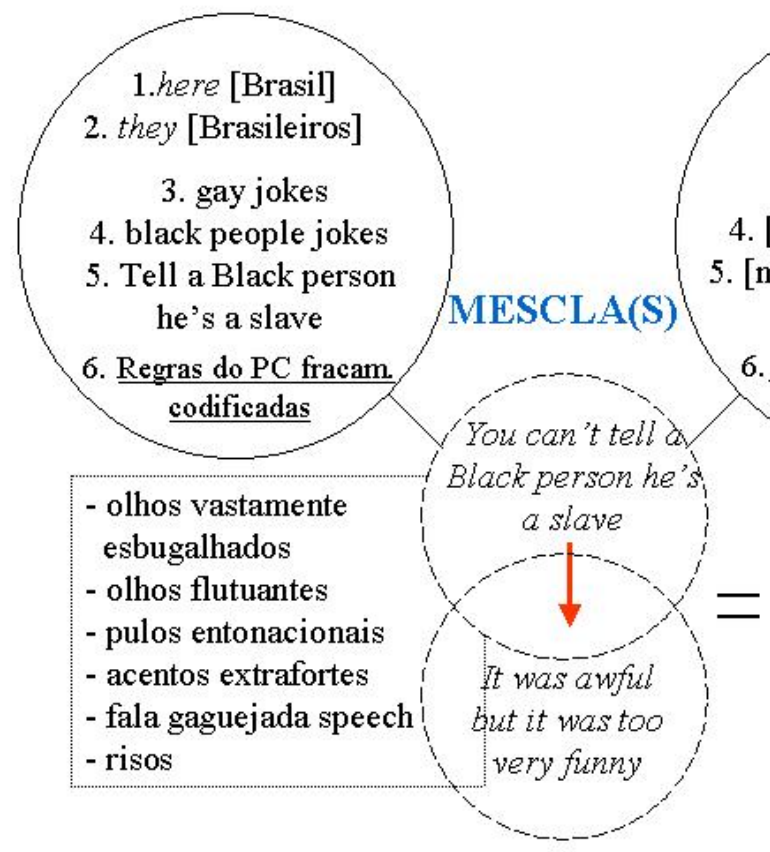

Figura 1: Mescla(s) do Espaço Intercultural

\section{INPUT 2}

1. [Suécia]

2. [Suecos]

3. [sem piadas gay]

4. [sem piadas sobre $\mathrm{PN}$ ]

. [never tell a Black person he's a slave]

6. Regras do PC fortem codificadas

\section{Espaço Intercultural} coparticipantes e para exagerar o efeito do confronto intercultural, realçado pelo uso hiperbolizado das pistas prosódicas. Em contraposição, o exemplo da voz crepitante mostrou como um episódio integral pode ser concebido em termos metafóricos, uma vez que se observou a ausência de tom como um marcador metafórico para distância e, com isto, como outra espécie de marcador de choque cultural exprimido cognitivamente no plano vocal.

Meios prosódicos e não verbais dão acesso a processos cognitivos de experiências interculturais e mostram como tais experiências mudam a visão de 
mundo das pessoas. Sendo assim, também vimos até que ponto uma compreensão dinâmica da Teoria da Mesclagem poderia servir como ferramenta para revelar tais processos para o pesquisador.

\section{Referências}

AUER, Peter. On the prosody and syntax of turncontinuations. In: COUPER-KUHLEN, Elizabeth; SELTING, Margret (Org.) Prosody in Conversation. Interactional Studies. Cambridge, New York: Cambridge University Press, 1996. 471 p. p. 57-100.

BERGMANN, Jörg. Ethnomethodologische Konversationsanalyse. In: FRITZ, Gerd; HUNDSNURSCHER, Fritz (Org.). Handbuch der Dialoganalyse. Tübingen: Max Niemeyer Verlag, 1994. 576 p. p. 3-16.

CHAFE, Wallace. Integration and Involvement in Speaking, Writing, and Oral Literature. In: TANNEN, Deborah (Org.). Spoken and Written Language: Exploring Orality and Literacy. Norwood, NJ: Ablex, 1982. p. 267. p. 35-53. ᄀ

CHARTERIS-BLACK, Jonathan. Corpus approaches to critical metaphor analysis. Basingstoke: Palgrave Macmillan, 2004. 278 p.

CIENKI, Alan. Cognitive linguistics, gesture studies, and multimodal communication. Cognitive Linguistics, Edmonton, v. 27, n. 4, p. 603-618, 2016.

CIENKI, Alan; MÜLLEr, Cornelia. Metaphor, Gesture, and Thought. In: GIBBS, Ray W. Jr. (Org.). The Cambridge Handbook of Metaphor and Thought. Cambridge: Cambridge University Press, 2008. 550 p. p. $483-501$.

DEIGNAN, Alice. Metaphor and Corpus Linguistics. Amsterdam: John Benjamins, 2005. 236 pages.

DEPPERMANN, Arnulf. How does 'cognition' matter to the analysis of talk-in-interaction? Language Sciences, Odense, v. 34, p. 746-767, 2012.

FAUCONNIER, Gilles. Mental Spaces: aspects of Meaning Construction in Natural Language. Cambridge: Cambridge University Press, 1985. $190 \mathrm{p}$.

FAUCONNIER, Gilles; TURNER, Mark. The Way We Think. New York: Basic Books, 2002. p. 440.

GOFFMAN, Erving. Forms of Talk. Philadelphia: University of Pennsylvania Press, 1981. 335 p.

GOODWIN, Charles. Participation, stance and affect in the organization of activities. Discourse \& Society, Barcelona, v. 18, n. 1, p. 53-73, 2007.
GÜNTHNER, Susanne. The Construction of Emotional Involvement in Everyday German Narratives - Interactive Uses of 'Dense Constructions'. Pragmatics, Viena, v. 21, n. 4, p. 573-592, 2011.

HAYASHI, Makoto; RAYMOND, Geoffrey; SIDNELL, Jack (Org.). Conversational repair and human understanding. Cambridge: Cambridge University Press, 2013. 396 p.

HERITAGE, John. Oh-prefaced responses to assessments: a method of modifying agreement/disagreement. In: FORD, Cecilia; FOX, Barbara; THOMPSON, Sandra (Org.). The Language of Turn and Sequence. Oxford: Oxford University Press, 2002. 304 p. p. 196-224.

JEFFERSON, Gail. A technique for inviting laughter and its subsequent acceptanze/declination. In: PSATHAS, George (Org.). Everyday Language: Studies in Ethnomethodology. New York: Irvington, 1979. 310 p. p. 79-96.

KÖVECSES, Zoltán. Metaphor: A Practical Introduction. Oxford: Oxford University Press, 2002.

KÖVECSES, Zoltán. Metaphor and Emotion. Language, Culture, and Body in Human Feeling. Cambridge: Cambridge University Press, 2003.

LAKOFF, George; JOHNSON, Mark. Metaphors We Live By. Chicago: The University of Chicago Press, 1980 [2003].

LANGACKER, Ronald W. Working toward a synthesis. Cognitive Linguistics, Edmonton, vol. 27, n. 4, p. 465-477, 2016.

LEE, Sinae. Creaky voice as a phonational device marking parenthetical segments in talk. Journal of Sociolinguistics, Auckland, Hong Kong, v. 15, n. 3, p. 275-302, 2015.

MITTELBERG, Irene; WAUGH, Linda R. Metonymy first, metaphor second: A cognitive-semiotic approach to multimodal figures of thought in cospeech gesture. In: FORCEVILLE, Charles J.; URIOS-APARISI, Eduardo (Org.). Multimodal Metaphor. Berlin, New York: Mouton de Gruyter, 2009. p. 470. p. 329-355.

MOURA, Heronides M. Metáforas e Regularidades Linguísticas. In: MIRANDA, Neusa S.; NAME, Maria. C. Lingüística e Cognição. Juíz de Fora: Editora UFJF, 2005. p. 09-119. 344p.

MÜLLER, Cornelia; CIENKI, Alan. Words, gestures, and beyond: Forms of multimodal metaphor in the use of spoken language. In: FORCEVILLE, Charles; URIOS-APARISI, Eduardo (Org.). Multimodal Metaphor. Berlin, New York: Mouton de Gruyter, 2009. 470 p. p. 297-328.

PERLMAN, Marcus; GIBBS, Raymond W. Jr. Sensorimotor simulation in speaking, gesturing, 
and understanding. In: MÜLLER, Cornelia et al. (Org.). Body - Language - Communication. An International Handbook on Multimodality in Human Interaction. Volume 1. Berlin, Boston: De Gruyter Mouton, p. 1138. p. 512-533.

POMERANTZ, Anita. Extreme case formulations. A way of legitimizing claims. Human Studies, Trier, v. 9, n. 2, p. 219-229, 1986.

SACKS, Harvey; SCHEGLOFF, Emanuel A.; JEFFERSON, Gail. A simplest systematics for the organization of turn-taking for conversation. Language, Washington, v. 50, p. 696-735, 1974.

SARDINHA, Tony. B. Metáfora. São Paulo: Parábola Editorial, 2007. p.167.

SCMITZ, H. Walter. Über kommunikative und extrakommunikative Betrachtungsweisen. In: KRALLMANN, Dieter; SCHMITZ, H. Walter (Org.). Perspektiven einer Kommunikationswissenschaft. Münster: Nodus Publikationen, 1998. 576 p. p. 315-326.

SCHRÖDER, Ulrike. Kommunikationstheoretische Fragestellungen in der kognitiven Metaphernforschung. Eine Betrachtung von ihren Anfängen bis zur Gegenwart. Tübingen: Gunter Narr Verlag, 2012. 363 p.

SCHRÖDER, Ulrike; CARNEIRO MENDES, Mariana. Diferenças no uso e nas funções de meios prosódicos na fala alemã e brasileira e suas implicações para a transcrição com GAT 2. In: Anais do I Congresso da ABEG, organizado por Helmut P. Galle e Valéria S. Pereira, São Paulo, Brazil, 9-11 November 2015, pp. 385-394. São Paulo: ABEG Editora Associação Brasileira de Estudos Germanísticos (ABEG), 2015.

SCHRÖDER, Ulrike; CARNEIRO MENDES, Mariana. Unterschiede im Gebrauch und in der Funktion prosodischer Merkmale im deutschen und brasilianischen Sprechen im Kontext des Transkribierens. In: JOHNEN, Thomas; SCHRÖDER, Ulrike; SAVEDRA, Mônica (Org.). Sprachgebrauch im Kontext: die deutsche Sprache im Kontakt, Vergleich und in Interaktion mit Brasilien. Stuttgart: ibidem. No prelo.

SCHÜTZ, Alfred. The stranger: An essay in Social Psychology. In: SCHÜTZ, Alfred (organizado e com introdução de Arvid Brodersen). Collected Papers II. Studies in Social Theory. The Hague: Martinus Nijhoff, 1976 [1944]. p. 286. p. 91-105.

SELTING, Margret. Emphatic speech style - with special focus on the prosodic signalling of heightened emotive involvement in conversation. Journal of Pragmatics, Brisbane, v. 22, n.3/4, p. 375-408, 1994.

SELTING, Margret. Verbal, vocal, and visual practices in conversational interaction. In: MÜLLER, Cornelia et al. (Org.). Body - Language -
Communication. An International Handbook on Multimodality in Human Interaction. Volume 1. Berlin, Boston: De Gruyter, 1138. pp. 589-609.

SELTING, Margret et al. Um sistema para transcrever a fala-em-interação: GAT 2. Traduzido e adaptado por Ulrike Schröder, Mariana Carneiro Mendes, Caroline Caputo Pires, Diogo Henrique Alves da Silva, Thiago da Cunha Nascimento e Flavia Fidelis de Paula (UFMG); com revisão técnica de Paulo Cortes Gago (UFJF/UFRJ). Veredas, Juíz de Fora, v. 20, n. 2, p. 6-61, 2016.

STIVERS, Tanya. When nodding is a token of affiliation. Research on Language \& Social Interaction, Loughborough, v. 41, n. 1, p. 31-57, 2008.

TISSARI, Heli. Conceptualizing Shame: Investigating Uses of the English Word Shame. In: Selected Proceedings of the 2005 Symposium on New Approaches in English Historical Lexis (HEL-LEX) (organizado por W McConchie et al.), Somerville, MA, 2005, p. 143-154. Sommerville: Cascadilla Proceedings Project.

\section{Anexo: Convenções de transcrição (GAT2)}

\begin{tabular}{|c|c|}
\hline $\begin{array}{ll}{[} & ] \\
{[} & ]\end{array}$ & $\begin{array}{l}\text { sobreposição e fala } \\
\text { simultânea }\end{array}$ \\
\hline${ }^{\circ} \mathrm{h} / \mathrm{h}^{\circ} ;{ }^{\circ} \mathrm{hh} / \mathrm{hh}{ }^{\circ}$ & ins-/expiração em \\
\hline (.) & $\begin{array}{l}\text { micro pausa estimada em } \\
\text { até } 0,2 \text { seg de duração } \\
\text { aprox. }\end{array}$ \\
\hline$(-)$ & $\begin{array}{l}\text { pausa curta estimada em } \\
\text { aprox. } 0,2-0,5 \text { seg de } \\
\text { duração }\end{array}$ \\
\hline$(--)$ & $\begin{array}{l}\text { pausa intermediária } \\
\text { estimada em aprox. 0,5 - } \\
0,8 \text { seg de duração }\end{array}$ \\
\hline$(---)$ & $\begin{array}{l}\text { pausa longa estimada em } \\
\text { aprox. 0,8 - 1,0 seg de } \\
\text { duração }\end{array}$ \\
\hline$(0.5) /(2.0)$ & $\begin{array}{l}\text { pausa mensurada em aprox. } \\
0,5 / 2,0 \text { seg de duração } \\
\text { (até o décimo de segundo) }\end{array}$ \\
\hline e_ah & $\begin{array}{l}\text { cliticizações dentro de } \\
\text { unidades }\end{array}$ \\
\hline$((r i))$ & $\begin{array}{l}\text { descrição de atividades } \\
\text { não verbais }\end{array}$ \\
\hline$<<$ rindo $>>$ & $\begin{array}{l}\text { descrição de atividades } \\
\text { acompanhando a fala com } \\
\text { indicação de escopo }\end{array}$ \\
\hline$\left(\begin{array}{ll}x x x & x x\end{array}\right)$ & $\begin{array}{l}\text { duas sílabas } \\
\text { incompreensíveis }\end{array}$ \\
\hline (posso) & termo presumido \\
\hline$=$ & $\begin{array}{l}\text { continuação rápida e } \\
\text { imediata com um novo } \\
\text { turno ou segmento } \\
\text { (latching) }\end{array}$ \\
\hline : & $\begin{array}{l}\text { alongamento, de aprox. } \\
0,2-0,5 \text { seg. }\end{array}$ \\
\hline$::$ & $\begin{array}{l}\text { alongamento, de aprox. } \\
0,5-0,8 \text { seg. }\end{array}$ \\
\hline$:::$ & $\begin{array}{l}\text { alongamento, de aprox. } \\
0,8-1,0 \text { seg. } \\
\text { ruptura (cut-off) por } \\
\text { fechamento glotal }\end{array}$ \\
\hline Sílaba & acento focal \\
\hline sílaba & acento secundário \\
\hline
\end{tabular}






\section{COMO CITAR ESSE ARTIGO}

SCHRODER, Ulrike. Falando sobre experiências interculturais: o 'salto' cognitivo para o universo do outro. Signo, Santa Cruz do Sul, v. 42, n. 75, dez. 2017. ISSN 1982-2014. Disponível em: <https://online.unisc.br/seer/index.php/signo/article/view/9803>. Acesso em: doi: http://dx.doi.org/10.17058/signo.v42i75.9803. 